\title{
Effect of Reinforcement, Load and sliding distance on Al-4.5\%wt Copper Matrix Hybrid Composites
}

\author{
K.C.Anantha Padmanbham, Mruthenjaya. M, Darshan B.G
}

\begin{abstract}
Aluminum is prospectively a significant material for tribological appliances for the reason that of its less density and superior thermal conductivity. However, aluminium by itself displays deprived tribological properties. Hence, the investigation of the tribological performance of aluminium based composite materials is flattering increasingly significant. Hence in the present research tribological behavior of Al-4.5\% wt copper reinforced with varying percentage of zircon sand $(2 \%-8 \%$ in increments of $2 \%$ ) with and without $2 \%$ wt graphite of hybrid composite samples prepared by friction stir casting technique.. To know the allocation of particles and bonding flanked by reinforcement with matrix, microstructure of the composites and base alloy were premeditated by means of "Optical and Scanning Electron Microscopy". The wear loss was computed employing pin on disc apparatus at room temp underneath dry sliding state. The investigation reveals that the wear rate of $\mathrm{Al}-4.5 \% \mathrm{wtCu}$ alloy effected by composition, load and speed.
\end{abstract}

Keyword- stir casting, Weight fraction, Optical micrographs, Scanning electron microscope, Micro hardness. Wear Rate.

\section{INTRODUCTION}

Aluminum alloys are extensively employed in aerospace as well as automobile industries owing to their less density, superior mechanical and corrosion characterisics [1]. The comparatively poor resistance to wear of aluminum alloys has restricted their utilization in definite tribological appliances. Aluminum metal matrix composites (Al MMCs) have revealed significant enhancement in wear properties contrast to usual aluminum alloys [2] Aluminum metal matrix composites (Al-MMCs) restraining particulate reinforcements are deemed as the hopeful solution for conveying enhanced wear resistance to aluminum alloys. Al MMCs are commonly reinforced with "continuous fibers, short or chopped fibers, whiskers and particulates". Attention has been intended towards particulate armored Al MMCs for their admirable mechanical and wears properties. Particulate armored composites are familiar in use owing to their availability, less cost, sovereignty of mechanical properties from particulate orientation [3] The assorted reinforcements that have been strived out to produce aluminum matrix composites(AMCs) are "Graphite, Silicon Carbide, Titanium Carbide, Tungsten, Boron, $\mathrm{Al}_{2} \mathrm{O}_{3}$, Flyash, $\mathrm{Zr}, \mathrm{TiB}_{2}$ ". Accumulation of rigid reinforcements such as "Silicon

Manuscript received on January 27, 2021.

Revised Manuscript received on February 22, 2021

Manuscript published on February 28, 2021

* Correspondence Author

K.C. Anantha Padmanbham*, Mechanical Engg Department, Don Bosco Institute of Technology, Bengaluru, India. Email: kcananth2000@gmail.com

Dr. Mruthenjaya. M, Mechanical Engg Department, JSS Academy of Teechnical Education, Bengaluru, India.Email: muthumkit@gmail.com

Darshan B.G, Mechanical Engg Department, Don Bosco Institute of Technology, Bengaluru,India. Email: dharshubg@gmail.com

Carbide, Alumina, And Titanium Carbide" improves hardness, strength and wear resistance of the composites [4-6].Among a variety of practicing routes, stir casting is one of the capable liquid metallurgy method employed to manufacture the composites. The process is easy, flexible, and appropriate for huge quantity production. The liquid metallurgy practice is the most inexpensive of all the available practice in producing of MMC [7].Wear is amputation of material from a solid surface by the sliding action of another solid and is caused by friction, fatigue or vibration [8]. Both sliding surfaces are scratched by these processes [9]. The sliding exteriors go through some distortion that may be purely elastic or some additional plastic deformation [10]. Wear reasons progressive damage involving material loss and occurs on the exterior of the component due to sliding. The sliding exteriors may be dry or lubricated and loss of material will be different in each case. The wear rate of the surface is also dependent on sliding speed, temperature; thermal, mechanical and chemical properties of the materials investigate. The wear of materials can occur due to "Adhesion, Abrasion, Surface Fatigue or Tribolo Chemical Reaction" [11].

\section{MATERIAL SELECTION}

In this investigation the materials used for the preparation of composite are: pure Aluminum, hardener, with $4.5 \%$ wt Copper powder as base matrix, Zircon sand with $40 \mu \mathrm{m}$ average particle size and Graphite of size $35 \mu \mathrm{m}$ as reinforcement materials, hexa chloroethane $\left(\mathrm{C}_{2} \mathrm{Cl}_{6}\right)$ and Scum powder. The chemical composition of $\mathrm{Al}-4.5 \% \mathrm{Cu}$ is given in the Table1.

Table1. Aluminum - 4.5 \% Copper Chemical Composition

\begin{tabular}{cc}
\hline Element & Weight \% \\
\hline $\mathrm{Cu}$ & 4.51 \\
$\mathrm{Mg}$ & 0.061 \\
$\mathrm{Si}$ & 0.52 \\
$\mathrm{Fe}$ & 0.59 \\
$\mathrm{Mn}$ & 0.13 \\
$\mathrm{Ni}$ & 0.06 \\
$\mathrm{~Pb}$ & 0.03 \\
$\mathrm{Sn}$ & 0.02 \\
$\mathrm{Ti}$ & 0.012 \\
$\mathrm{Zn}$ & 0.12 \\
$\mathrm{Al}$ & Balance \\
\hline
\end{tabular}

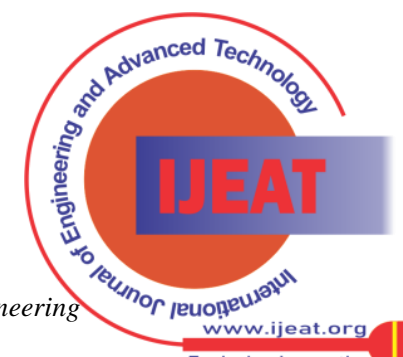




\section{EXPERIMENTAL PROCEDURE}

The present investigation involves the fabrication of composites by Stir Casting Technique is most effective and simplest techniques of manufacturing the composite. Composites manufactured by means of this method entail liquefying of the matrix subsequent by the accumulation of reinforcement particles to liquefy with immediate stirring, followed by casting in a mould. Aluminium with $98.5 \%$ purity is fed into the graphite crucible and heated in an electrical resistance furnace. Aluminium starts melting, when furnace temperature is raised to $750{ }^{\circ} \mathrm{C}$, at that time $4.5 \mathrm{wt} . \%$ of $\mathrm{Cu}$ was introduced into the pure molten $\mathrm{Al}$ along with hardener $(50 \% \mathrm{Al}$ and $50 \% \mathrm{Cu})$. Hexachloroethane tablets were added to confiscate impurities as well as gases from the surface of the molten metal at around $750{ }^{\circ} \mathrm{C}$ and scum powder was used as a slag removing agent. The mixture was further heated up to $800{ }^{\circ} \mathrm{C}$ to ensure proper melting of the matrix alloy. Table 2 shows the test samples of aluminium alloy matrix and composites with different weight percentages of $\mathrm{ZrSiO}_{4}$ and graphite. $\mathrm{ZrSiO}_{4}$ particles of an average size of 40 microns and graphite size of 35 microns were selected and pre heated to a temperature of $200{ }^{\circ} \mathrm{C}$ in order to provide fine bond among the alloy matrix and reinforcement. Initially four samples $\left(Z_{2}-Z_{5}\right)$ of casting were obtained by adding $\mathrm{ZrSiO}_{4}$ in to the molten matrix alloy with varying percentage of reinforcement from $0 \%$ up to $8 \%$ in steps $2 \%$. To ensure uniformity of mixing and complete insertion of particles, the mixture was stirred for 3-5 minutes thoroughly by using a mechanical stirrer. The temp of furnace was proscribed between $760{ }^{\circ} \mathrm{C}$ and $780{ }^{\circ} \mathrm{C}$ in the final stirring stage and pouring temperature was controlled at $750{ }^{\circ} \mathrm{C}$. After thorough mixing, slags and oxides were removed and then mixture was poured in to the preheated finger shaped mould die to produce required shape of castings. The same procedure was repeated to prepare another set of four cast samples $\left(\mathrm{Z}_{6}-\mathrm{Z}_{9}\right)$ with the constant addition of $2 \%$ by weight of graphite by varying $\mathrm{ZrSiO}_{4}$ in steps of $2 \%$ up to $8 \%$.

Table 2. Composite test samples considered

\begin{tabular}{|c|c|}
\hline Sample No. & Composition of test samples \\
\hline $\mathrm{Z}_{1}$ & $\mathrm{Al}-4.5 \% \mathrm{Cu}$ Matrix \\
\hline $\mathrm{Z}_{2}$ & $\mathrm{Al}-4.5 \% \mathrm{Cu}+2 \% \mathrm{ZrSiO}_{4}$ \\
\hline $\mathrm{Z}_{3}$ & $\mathrm{Al}-4.5 \% \mathrm{Cu}+4 \% \mathrm{ZrSiO}_{4}$ \\
\hline $\mathrm{Z}_{4}$ & $\mathrm{Al}-4.5 \% \mathrm{Cu}+6 \% \mathrm{ZrSiO}_{4}$ \\
\hline $\mathrm{Z}_{5}$ & $\mathrm{Al}-4.5 \% \mathrm{Cu}+8 \% \mathrm{ZrSiO}_{4}$ \\
\hline $\mathrm{Z}_{6}$ & $\mathrm{Al}-4.5 \% \mathrm{Cu}+2 \% \mathrm{ZrSiO}_{4}+2 \% \mathrm{Gr}$ \\
\hline $\mathrm{Z}_{7}$ & $\mathrm{Al}-4.5 \% \mathrm{Cu}+4 \% \mathrm{ZrSiO}_{4}+2 \% \mathrm{Gr}$ \\
\hline $\mathrm{Z}_{8}$ & $\mathrm{Al}-4.5 \% \mathrm{Cu}+6 \% \mathrm{ZrSiO}_{4}+2 \% \mathrm{Gr}$ \\
\hline $\mathrm{Z}_{9}$ & $\mathrm{Al}-4.5 \% \mathrm{Cu}+8 \% \mathrm{ZrSiO}_{4}+2 \% \mathrm{Gr}$ \\
\hline
\end{tabular}

The composite samples were metallographic ally polished and micro structural characterization studies were conducted to examine the allocation of reinforcement throughout the matrix. This is accomplished by using Nikon Microscope LV150 with Clemex Image Analyzer. The prepared composite samples were etched using Keller's reagent to study the microstructure characterization. Fig. 1 shows the microstructure of selected specimens of heat treated composite specimens of $2 \%$ zircon and $8 \%$ zircon with and without the accumulation of graphite in to the matrix alloy. The Pinon disc equipment was used to find out the sliding wear traits of the composite. samples of size $10 \mathrm{~mm}$ diameter and $30 \mathrm{~mm}$ length were slice from the cast samples, machined and then polished. The contact exterior of the cast sample (pin) has to be flat and will be in get in touch with with the revolving disk. For the period of the test, the pin is detained pressed in opposition to a revolving EN32 steel disc (hardness of 65HRC) by applying load that operates as counterweight and balances the pin. The track diameter was fixed to $100 \mathrm{~mm}$ the factors such as the load, sliding speed and sliding distance were varied. Weight loss of every sample was acquired by weighing the sample before and after the trial by a single pan electronic weighing apparatus with an accuracy of $0.0001 \mathrm{~g}$ after thorough uncontaminated with acetone solution.One of the test samples from each combination was applied with a $5 \mathrm{~kg}$ load. The speed of the disc was set to $800 \mathrm{rpm}$ and the wear loss in milligrams of the pin was tabularized for 12 minutes constant. The track radius of rotation was kept at 50 $\mathrm{mm}$ of the disc. Out of all the 9 composition the 3 of composition, the base metal, the $\mathrm{Al}+4.5 \% \mathrm{Wt} \mathrm{Cu}+8 \% \mathrm{Wt}$ Zircon sand and the $\mathrm{Al}+4.5 \% \mathrm{Wt} \mathrm{Cu}+2 \% \mathrm{Wt}$ Graphite + $4 \% \mathrm{Wt}$ Zircon sand were selected.These were again tested against loads of $3 \mathrm{~kg}, 4 \mathrm{~kg}$ and $5 \mathrm{~kg}$, each of each for sliding distance of $1000 \mathrm{mts}, 2000 \mathrm{mts}$ and $3000 \mathrm{mts}$ and the wear loss in milligrams of the pin were tabulated. Throughout the test velocity of the disc was set to $800 \mathrm{rpm}$ and track radius of rotation was set to $50 \mathrm{~mm}$ of the disc. Weight loss was deemed for wear investigation (i.e. the variation among the initial and final weight). Formula used for finding weight loss is as shown below

$$
\begin{gathered}
\text { Weight loss }(\mathrm{WL})=\text { Initial weight }- \text { Final weight } \\
=\mathrm{W} 1-\mathrm{W} 2 \text { grams }
\end{gathered}
$$

\section{RESULTS AND DISCUSSIONS}

\subsection{Metallographic studies and SEM analysis}

Micro structures of Aluminum - $4.5 \%$ Copper armored with Zircon sand and Graphite composite samples were examined by metallographic ally as shown in Fig. 4.11 [a, b, c] and 4.12[a, b, c].The micro graphs and SEM images clearly show that minimal porosity, excellent bond between the matrix alloy, no indication of cracks in castings, low agglomeration seclusion of particles correlated to proper process parameter employed for casting. The whirlpool produced in the stirring process ruptures solid dendrites due to friction among particles and $\mathrm{Al}-4.5 \% \mathrm{Cu}$ matrix alloy, which further produces a uniform allocation of particles.

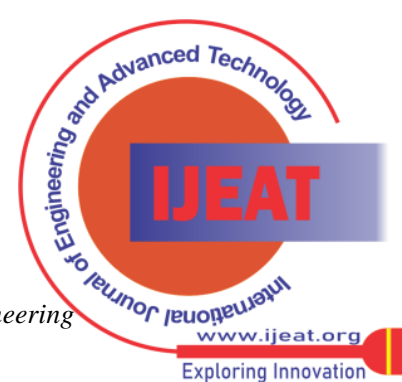



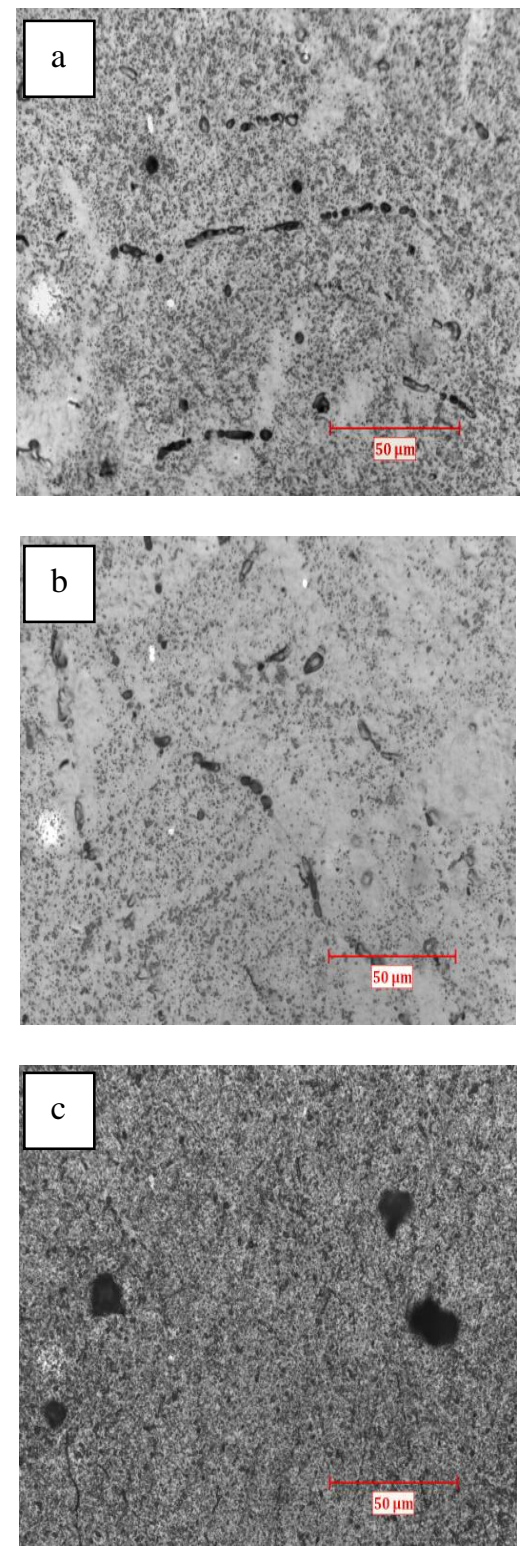

Fig 4.110ptical micrographs (a) Aluminum - $4.5 \%$ Copper (b) Aluminum - $4.5 \%$ Copper $+8 \%$ Zircon sand(c) Aluminum - $4.5 \%$ Copper $+8 \%$ Zircon Sand $+2 \%$ Graphite

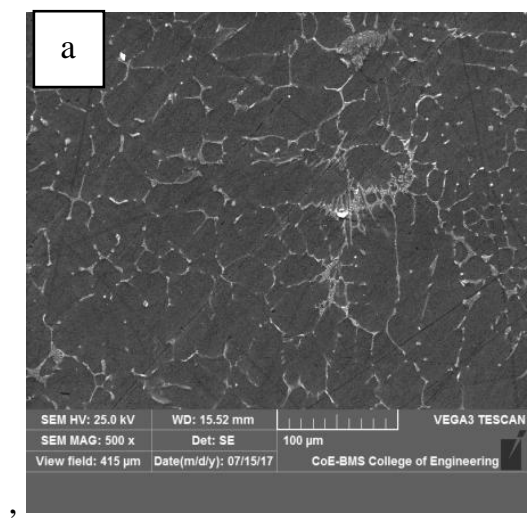

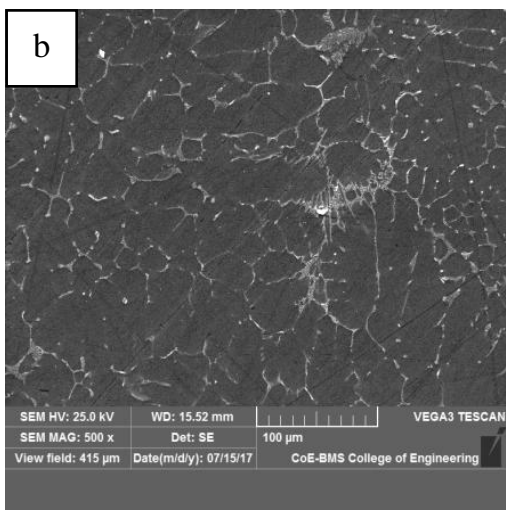

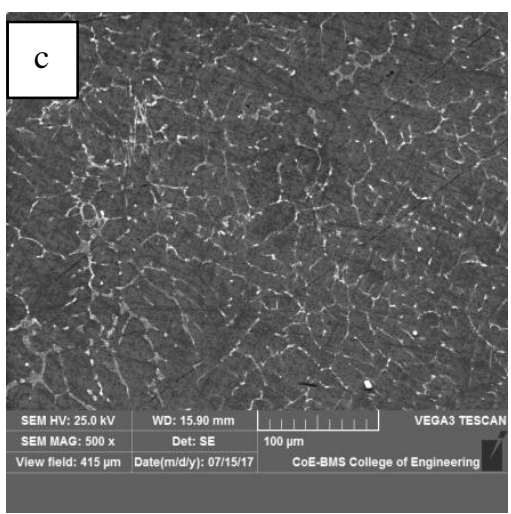

Fig 4.12 SEM photographs of (a) Aluminum - $4.5 \%$ Copper (b) Aluminum - $4.5 \%$ Copper $+8 \%$ Zircon Sand, (c) and Aluminum - $4.5 \%$ Copper $+8 \%$ Zircon Sand $+2 \%$ Graphite

\subsection{Preliminary Wear Test}

Fig. 5.19 illustrates the results of Wear performance of cast $\mathrm{Al}-4.5 \% \mathrm{Cu}$ as well as its composites in dry Sliding condition manufactured with varying wt.\% of Zircon reinforcement particles (2\% -8\% in increments of $2 \%$ ) with $0 \%$ wt and $2 \%$ wt of Graphite. Also it was observed that for a specific reinforcement substance, the composites have superior wear résistance while judge against the matrix alloy which is similar to other researchers $(33,46,47,52$, and 61$)$. Since the reinforcements perform as the load-bearing elements at the commencement of rasping, perform as inhibitors as opposed to plastic crook and adhesion of the matrix material.

The composites wear rate reduces by raise in wt.\% of zircon particles, similar to other researchers $(33,46,47,52$, and 61). This can be attributed to a certainty that the amalgamation of tough and the abrasive nature of Zircon particles improves the hardness of composites. The wear résistance enhancement and seizure resistance of the material is mainly due to improvement in the hardness. While reinforced grains are sturdily bonded with the base matrix, they shield the surface in opposition to the stern destructive deed by the counter face. The sturdy link between base matrix as well as reinforcement is the most important aspect that persuades the wear performance that plays a vital function in shifting loads as of the base matrix to tough reinforced particles. Furthermore it is observed that slighter permeability in the composite substances can enlarge the necessary length of fracture proliferation to an array by further cracks to the reason for delimitation and enhances the wear of the composite

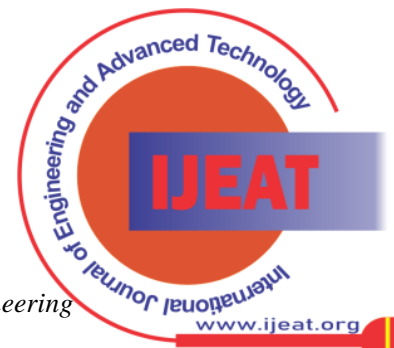


The wear further diminishes with the addition of $2 \%$ wt of graphite, similar to other researchers $(50,56 \& 57)$.This reduction in wear may be owing to the accumulation of graphite particles which that execute like a lubricant and formulates a tinny film amongst the pairing surfaces. In dry sliding conditions aluminum-graphite composites end resulted in the progress of an interminable layer of firm lubricant that had produced above tribo-surfaces. This happens as a consequence of incising of graphite particles which are placed under the gliding exterior of composite that assists in dropping the magnitude of shear stress, which allays the plastic distortion in the second surface area, hinders metal-to-metal contact furthermore executes like firm lubricant amongst two sliding exteriors consequently wear decreases.

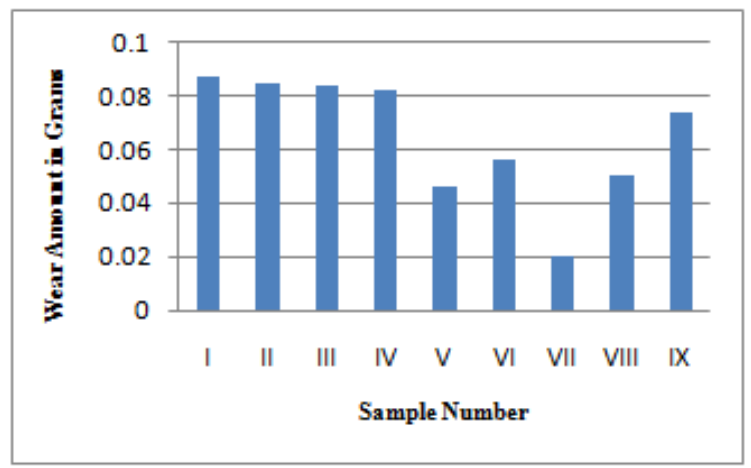

Preliminary wear test of all compositions

From the above results seen three compositions considered for comparison were

(i) I. Base material $(\mathrm{Al}+4.5 \% \mathrm{Cu})$

(ii) $\mathrm{V}$ composition $(\mathrm{Al}+4.5 \% \mathrm{Cu}+8 \%$ Zircon Sand $)$

(iii) VII composition $(\mathrm{Al}+4.5 \% \mathrm{Cu}+4 \%$ Zircon Sand $+2 \%$ Graphite)

\subsection{Wear Test Selected Composition for Constant Load} Influence of sliding distance on wear behavior:

From Fig.4.31 to Fig.4.33, it is examined that the raise in distance wear reduces. The negative slope confirms an indirect correlation between the sliding distance and wear rate. Wear rate reduced to a greater extent when gliding distance raises as of $1000 \mathrm{~m}$ toward $3000 \mathrm{~m}$. This tendency is owing to the existence of the zirconium reinforcements which projects out of the composite surface are sharp and reduces the contact surface area between two sliding surfaces and decreases the wear. More raise in the gliding distance to 3000 $\mathrm{m}$, the projections of tough reinforcements become blunt and decrease the contact region flanked by the composite specimen with the disc that provides abrasion resistance and also the adding graphite into the composites develops the resistance to wear performance owing to its nature lubrication characteristic. This graphite spreads on the gliding pin surface and creates a film that decreases wear.

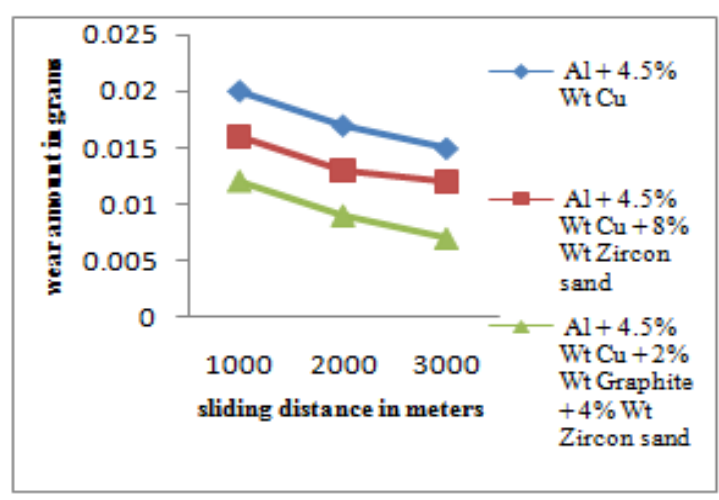

Fig 4.31 Wear at Applied Load of $30 \mathrm{~N}$ and Speed of 800 RPM

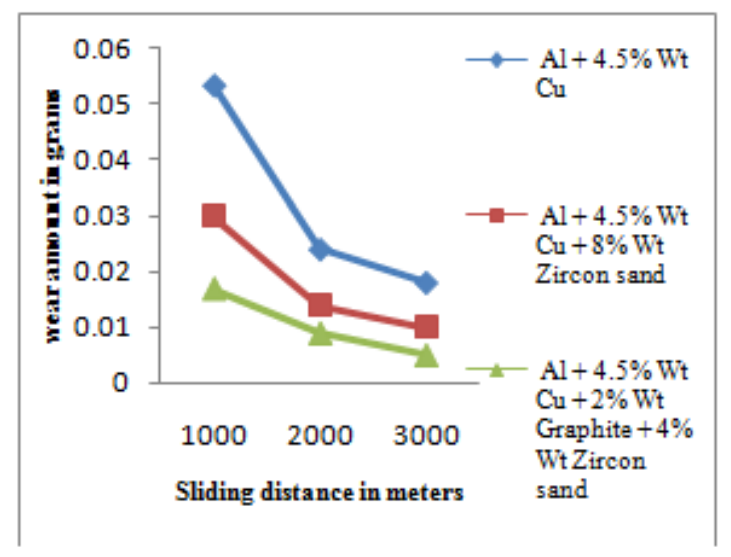

Fig 4.32 Wear at Applied Load of 40N and Speed of $800 \mathrm{Kpm}$

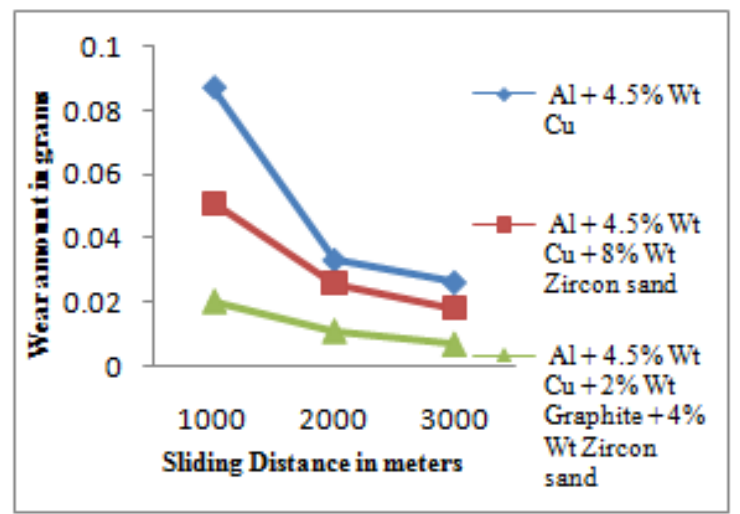

\section{Fig 4.33 Wear at Applied Load of 50N and Speed of 800 RPM}

Influence of applied load on wear behavior:

From figures 4.34 to 4.36 enlighten the tendency pursued by the applied load on wear performance. When load raises as of $30 \mathrm{~N}$ toward $500 \mathrm{~N}$ because of rubbing action among the disc and composite sample causes the wear. Plastic deformations as well as gouging are the two reasons for material taking away throughout the wear procedure in aluminium composites. It is examined that through the raise in the applied load starting $40 \mathrm{~N}$ toward $60 \mathrm{~N}$ within strides of $10 \mathrm{~N}$ the wear rate also raises nearly in linear proportion. This tendency in the plot owes to enhance in contact pressure between the composite specimen and disc that cause larger surface damage.

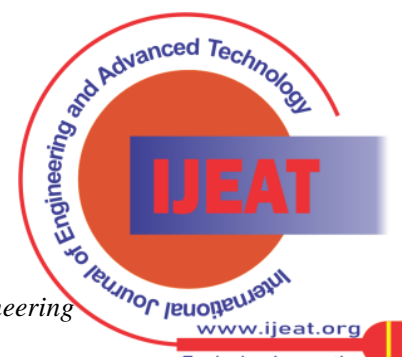


Amplified wear paces with raised load can be accredited to the certainty that at high loads, here is a propensity for enormous plastic distortion which encourages the amount of wears debris creation foremost to high wear rates. The larger the amount of plastic distortion, the more will be the possibility of sub exterior fracturing that leads to bigger material taking away. Therefore it can be brought to a closed that the wear pace was established to rise by a raise in applied load. Whereas rigorous wear phenomenon is caused due to adhesion when applied normal load raise from $55 \mathrm{~N}$ to $60 \mathrm{~N}$ and a similar phenomenon is observed by the other researchers.

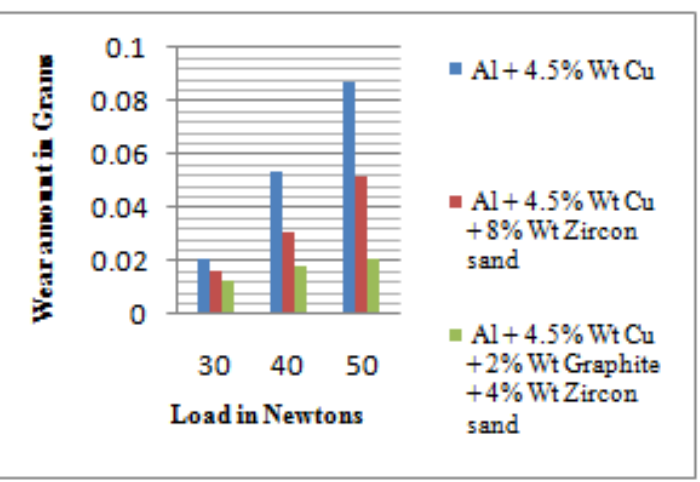

Fig 4.34 Sliding Distance of 1000 Meters

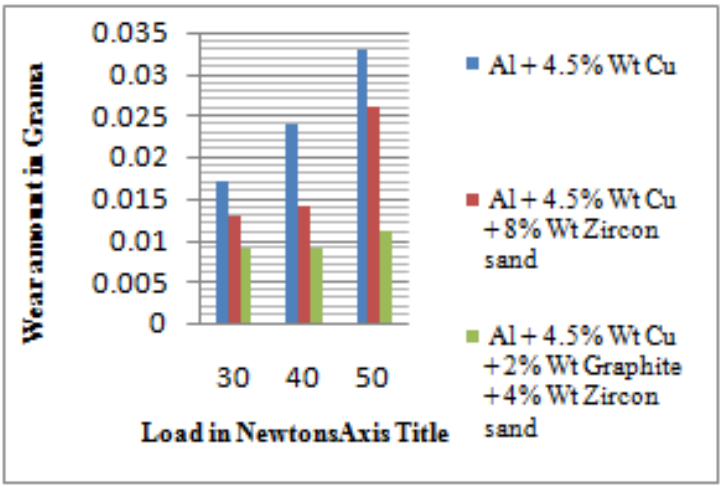

Fig 4.35 Sliding Distance of 2000 Meters

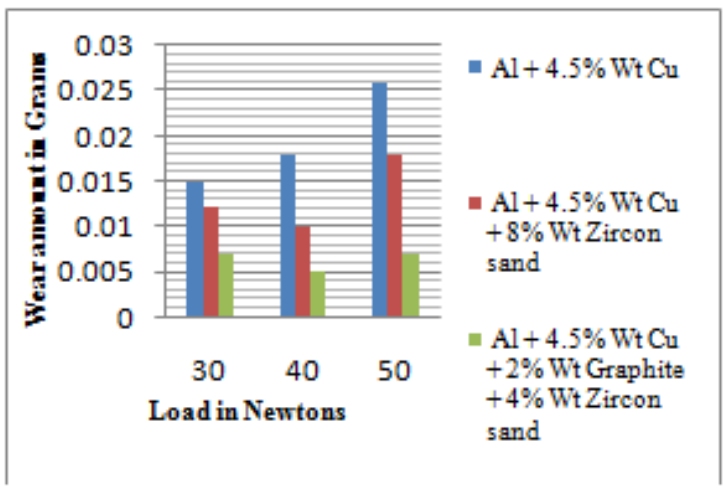

Fig 4.36 Sliding Distance of 3000 Meters

\section{CONCLUSIONS}

9 series of composites consisting Al-4.5\% wt copper as the base material by varying the percentage of zircon sand in the increments of $2 \%$ wt. upto $8 \%$ wt. with and without $2 \%$ wt graphite were successfully fabricated using stir casting method

$>$ The Optical, SEM micrographs revealed the presence of zircon sand and graphite composite with homogeneous dispersion
$>$ varying the speed, load and distance for the above selected compositions and the base composition, we have got the best results in, " $\mathrm{AL}+4.5 \% \mathrm{CU}+4 \%$ Zircon Sand $+2 \%$ Graphite "

\section{ACKNOWLEDGMENT}

The authors express their thanks to HOD and staff of Mechanical Engineering Department, to the Principal of DBIT and to the Management of Wayanamac Education Trust, Bangalore, for the support and encouragement during this design and analysis of injection mold tool.

\section{REFERENCES}

1. Sharma SC. The sliding wear behavior of Al6061-garnet particulate composites. Wear 2001; 249:1036-45.

2. Lee CS. Wear behavior of aluminum matrix composite material. In: Kim YH, Han KS, Lim L, editors. J Mat Sci 1992; 27:793-800.

3. Mcdanels DL. "Analysis Of Stress-Strain Fracture, And Ductilitybehavior Of Aluminum Matrix Composites Containing Discontinuous Silicon Carbide". Metall Trans 1985;16A:1105.

4. A.Baradeswaran "Effect of Graphite Content on Tribological behaviour of Aluminium alloy GraphiteComposite", European Journal of Scientific Research, Vol.53 No.2 (2011), pp.163- 170.

5. K. R. Suresh, H.B. Niranjan, P. Martin Jabraj, M.P. Chowdaiah. 2003. Tensile and wear properties ofaluminium composites. Wear. 255: 638-642.

6. T.V.Christy, N.Murugan and S.Kumar, "A Comparative Study on the Microstructures and MechanicalProperties of Al 6061 Alloy and the MMC Al 6061/TiB2/12P”, Journal of Minerals\& MaterialsCharacterization \& Engineering, 2010 Vol. 9, No.1, pp.57-65.

7. Surappa, M.K., "Microstructure Evolution during Solidification of DRMMCs: State of the Art," Journal of Materials Processing Technology, 63: 325-333. 3078 A. MANNA ET AL.1997.

8. M.J.Neale, ed., 1973. Tribology Handbook Butterworths (1973), London, Butterworths: London.

9. Archard, J., 1953. Contact and rubbing of flat surfaces, Journal of applied physics 24(8), p. 981-988

10. Quinn, T.F.J., ed., 1991. Physical analysis for tribology, Cambridge University Press: 10 Stamford Road, Melbourne, Australia.

11. Sanjeev Das.; Das, E. K.; and Das, E.S. (2006). Ageing behaviour of Al-4.5 wt. \% Cu matrix alloy reinforced with $\mathrm{Al}_{2} \mathrm{O}_{3}$ and $\mathrm{ZrSiO}_{4}$ particulate varying particle size. Journal of material science, 41, 5402-5406.

12. Mousavi Abarghouie, S.M.R.; and Seyed Reihani, S.M. (2010). Aging behaviour of a $2024 \mathrm{Al}$ alloy-SiC $\mathrm{P}_{\mathrm{p}}$ composite. Materials and Design, 31, 2368-2374.

13. Rajendra kumar kushwaha.; and Suhail ahmad siddiqui. (2014) Characterization $\mathrm{Al}-4.5 \% \mathrm{Cu}$ alloy and study of wear resistance. International Journal of Scientific Engineering and Technology, 3(3), 263-266.

14. Mahagundappa, M. Benal.; and Shivanand, H.K. (2007). Effects of reinforcement's content and ageing durations on wear characteristics of $\mathrm{Al}$ (6061) based hybrid composites. Wear, 262, 759-763.

15. Gokul Prashanth, D.; Manoj Karthick, C.; Mahmoodul Hasan, A; and Jeeno Amarnath, K.C. (2015). Characterization of as cast and heat treated aluminium based hybrid metal matrix composites International Journal of Scientific \& Engineering Research, 6(8), 740-745.

16. Thirumaleshwara Bhat.; Shreeranga Bhat.; and Girish Kumar. (2015) Effect of heat treatment variables on the abrasive wear behavior of $\mathrm{Al}-6061$ alloy and $\mathrm{Al}$ 6061-SiC $\mathrm{P}_{\mathrm{P}}$ composites using taguchi technique. American Journal of Materials Science, 5(3C), 151-156.

17. Uvaraja, V.C.; Natarajan, N.; Sivakumar, K.; Jegadheeshwaran, S.; and Sudhakar, S. (2015). Tribological behavior of heat treated Al 7075 aluminium matrix composites, Indian Journal of Engineering \& Material Science, 22, 51-61. 
18. Somashekhar, P. H.; Sharma, K.V.; and Girisha, H. N. (2018). Effect of heat treatment on tensile and hardness properties of aluminium-7075 alloy reinforced with graphite and bagasse-ash composites, International organization of Scientific Research, 8(8), 38-43.

19. Jones, D.R.H.; and Ashby, M.F. (2006). Engineering Materials-2: An introduction to microstructures, processing and design, ( ${ }^{\text {rd }}$ Edition), Butterworth-Heinemann, Woburn, UK.

\section{AUTHORS PROFILE}

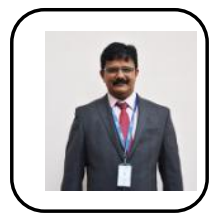

K C Anantha Padmanabham working as Associate Professor in the Department of Mechanical Engineering, Don Bosco Institute of Technology with 22 years of Teaching and 3years of Industrial Experience. The author has submitted Thesis to VTU, Belgaum. The author has published two journal papers, four papers in international conference and four papers in national conference, life member of ISTE.Email:kcananth2000@gmail.com

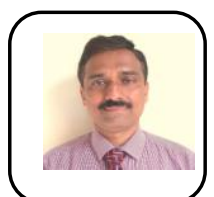

Dr.Mruthenjaya.M working as Associate Professor in the Department of Mechanical Engineering, , JSS Academy of Technical Education, Bengaluru with 28years of Teaching and 3years of Industrial Experience. The author has published 4journal papers and 7 papers in international conferences, life member of ISTE and Institute of Engineers Email: muthumkit@ gmail.com

Dharshan B.G working as Associate Professor in the Department of Mechanical Engineering, Don Bosco Institute of Technology with 16 years of Teaching and 5 years of Industrial Experience. Presently author is pursuing research in the area of Polymer Matrix Nan composites. The author has published two journal papers, three papers in international conference and two papers in national conference.Email:dharsubg@gmail.com

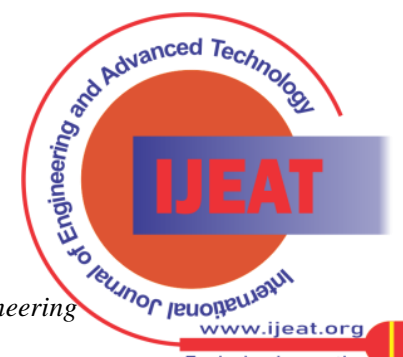

